\title{
BMJ Open A questionnaire survey exploring healthcare professionals' attitudes towards teamwork and safety in acute care areas in South Korea
}

\author{
Sung Eun Kim, ${ }^{1}$ Chan Woong Kim, ${ }^{1}$ Sang Jin Lee, ${ }^{1}$ Je Hyeok Oh, ${ }^{1}$ \\ Dong Hoon Lee, ${ }^{1}$ Tae Ho Lim, ${ }^{2}$ Hyuk Joong Choi, ${ }^{2}$ Hyun Soo Chung, ${ }^{3}$ \\ Ji Yeong Ryu, ${ }^{4}$ Hye Young Jang, ${ }^{5}$ Yoon Hee Choi, ${ }^{6}$ Su Jin Kim, ${ }^{7}$ Jin Hee Jung ${ }^{8}$
}

To cite: Kim SE, Kim CW, Lee SJ, et al. A questionnaire survey exploring healthcare professionals' attitudes towards teamwork and safety in acute care areas in South Korea. BMJ Open 2015;5: e007881. doi:10.1136/ bmjopen-2015-007881

- Prepublication history for this paper is available online. To view these files please visit the journal online (http://dx.doi.org/10.1136/ bmjopen-2015-007881).

Received 6 February 2015 Revised 2 July 2015 Accepted 2 July 2015

CrossMark

For numbered affiliations see end of article.

Correspondence to Dr Chan Woong Kim; whenever@cau.ac.kr

\section{ABSTRACT}

Objectives: Although human factors are important in terms of patient safety, there have been very few reports on the attitudes of healthcare professionals working in acute care settings in South Korea. In the present study, we investigated the attitudes of such professionals, their cultures and their management systems.

Design: A questionnaire survey with 65 items covering nine themes affecting patient safety. Nine themes were compared via a three-or-more-way analysis of variance, with interaction, followed by multiple comparisons among several groups.

Setting: Intensive care units, emergency departments and surgical units of nine urban hospitals.

Participants: 592 nurses and 160 physicians.

Intervention: None.

Outcome measures: Mean scores using a five-point scale and combined response scores for each of the nine themes.

Results: The mean score for information-sharing was the highest $(3.78 \pm 0.49)$ and that for confidence/ assertion was the lowest $(2.97 \pm 0.34)$. The mean scores for teamwork, error management, work value, organisational climate, leadership, stress and fatigue level, and error/procedural compliance were intermediate. Physicians showed lower scores in leadership and higher scores in information-sharing than nurses. Respondents with 24 months or less of a clinical career showed higher scores in leadership, stress and fatigue, and error scores and lower scores in work value than more experienced respondents.

Conclusions: Our results suggest that medical personnel in Korea are relatively reluctant to disclose error or assert their different opinions with others. Many did not adequately recognise the negative effects of fatigue and stress, attributed errors to personal incompetence, and error-management systems were inadequate. Discrepancies in leadership and information-sharing were evident between professional groups, and leadership, stress, fatigue level, work value and error scores varied with the length of work experience. These can be used as baseline data to establish training programmes for patient safety in Korea.

\section{Strengths and limitations of this study}

- This study is a questionnaire survey to investigate the attitudes of medical team members in critical areas of hospital, hospital and national culture and management systems towards human factors and patient safety.

- The survey comprised nine themes: leadership, confidence-assertion, information-sharing, teamwork, awareness of stress and fatigue, work values, organisational climate, error/procedural compliance and error management.

- This study suggests that there is a rigid culture which does not encourage open discussion and feedback on different opinions with other colleagues, high value on the technical skill and competence and high dependency on the decisions of the senior staff members relatively. In addition, hospital and national culture and management systems towards human factors and patient safety were still insufficient.

- The data are from teaching hospitals, which limits the generalisability of the results, and further surveys need to extend to different types of medical institutions.

\section{INTRODUCTION}

In addition to medical knowledge and technical skills, the importance of human factors is being increasingly emphasised for safe and high-quality medical care and for decreasing medical error incidents. ${ }^{1-4}$ Such human factors include non-technical skills such as respectful leadership, information-sharing, communication, teamwork and good decision-making. Inadequate management of stress and workload causes medical errors. ${ }^{5}{ }^{6}$

In critical situations, team members at all levels must work together to competently perform critical tasks. ${ }^{7}$ In particular, team performance and coordination play vital roles in terms of patient safety. Increasing 
emphasis is placed on the effective application of human factors to patient care. Many countries have developed relevant training courses.

Attitudes towards human factors relevant to patient safety are formed not only personally, but are also influenced by group characteristics such as occupation, organisation and culture. ${ }^{9-13}$ Such attitudes are also strongly affected by individual hospital and national medical systems. ${ }^{14}$ Therefore, it is important that there is a common consensus across hospital departments and units across the country and that this is reflected in the healthcare management system. Medical professionals must be trained to recognise the importance of human factors and to develop appropriate management methods.

Many tools that measure attitudes have been developed and applied; these include the Operating Room Management Attitudes Questionnaire (ORMAQ). Data collected using such tools are used to identify the prevailing attitudes towards safety and the organisational culture; to establish goals and strategies for training; to evaluate and upgrade training programmes; and to draw comparisons with data from other countries. ${ }^{12} 1315$ Such information can also be used as a component of a quality-assurance programme. ${ }^{1}{ }^{12}$

In Korea, there is an increasing number of training programmes on patient safety for physicians and nurses within hospitals and the national medical system; these reflect not only the need for healthcare accreditation but also the societal demand that patient care be safe. Individualised training courses for small units, such as private hospitals and associations, are available. However, there are a limited number of universal and integral training courses. Therefore, a comprehensive evaluation of the current situation is required to allow us to define strategies for education in human factors. However, although there are few reports on a small number of job-specific human factors, ${ }^{16}{ }^{17}$ there are very few reports on the attitudes of medical team members working in critical care settings in Korea.

Therefore, in this study, we explored the attitudes of medical team members working in critical care settings within hospitals and management systems of South Korea towards human factors relevant to patient safety. Our data serve as a baseline for the development of training programmes and improvement of management systems that may enhance safety.

\section{METHOD}

This study was approved by the institutional review board (IRB). All participants provided written informed consent prior to participation. The survey was conducted between October 2011 and March 2012.

\section{Participants}

The participants were nurses and physicians working in nine urban teaching hospitals in South Korea. The nurses worked in intensive care units, emergency departments and operating suites; the doctors worked as residents, specialists and interns in clinical departments caring for patients treated in these settings. The number of nurses who work in this setting is 750 and that of doctors is 560 approximately in nine hospitals.

\section{Questionnaire and procedure}

The questionnaire was anonymous; the demographic data collected included age, sex, length of clinical career, occupation and work area for nurses, and specialty for physicians.

We used the ORMAQ (with minor changes in wording) to survey attitudes towards teamwork and safety; the changes sought to accurately describe the work environment. For example, 'operating theatre' was changed to 'medical team.' The questionnaire had nine themes: leadership, confidence/assertion, information-sharing, teamwork, stress and fatigue, work values, organisational climate, error and procedural compliance and error management. There were 65 items; all were answered using a scale ranging from 1 (strongly disagree) to 5 (strongly agree). Copies of the questionnaire were given to each department, and completed questionnaires were returned to our laboratory in prestamped self-addressed envelopes.

\section{Data analysis}

We calculated distribution ratios for sex, occupation, working area (nurses) and specialty (physicians); we divided the lengths of clinical careers into units of 24 months. The medians and quantiles of age and length of clinical career were calculated.

A mean score for each item was calculated on the basis of responses on the five-point scale. We recognised three types of response. 'Strongly agree' and 'slightly agree' were considered to be 'agree'; 'average' was considered to be 'neutral'; and 'slightly disagree' and 'strongly disagree' were considered to be 'disagree'.

To compare each theme among groups, the response scores of items within each of the nine themes were combined to allow means and SDs to be calculated. Items were reverse-scored when necessary; thus, the higher the score, the more positive the attitude. Internal reliability was measured by calculating Cronbach's $\alpha$ (again, with reverse scoring when necessary).

The mean values for each theme were compared via a three-or-more-way analysis of variance, with interaction, followed by multiple comparisons among several groups varying in any of age, sex, clinical career length or occupation.

A result was considered significant at the $5 \%$ critical level $(p<0.05)$. All statistical analyses were performed using IBM SPSS Statistics software V.20 (IBM Inc., Armonk, New York, USA).

\section{RESULTS}

The overall response rate was $69.6 \%(752 / 1080)$. The response rate for nurses was $82.2 \%(592 / 720)$ and that 
Table 1 General characteristics of respondents

Median and quartiles or $\mathbf{n}(\%)$
Male

Age (years)

Clinical career (months)

Clinical career $\leq 24$ months

Nurses

Intensive care unit

Emergency department

Operating room

Physicians

Specialist

Resident

Intern
$141(18.8 \%)$

$28(26-33)$

$41(15-87)$

$289(38.4 \%)$

$262(44.3 \%)$

$160(27.0 \%)$

$140(23.7 \%)$

$28(17.5 \%)$

$98(61.3 \%)$

$34(21.3 \%)$ of doctors $44.4 \%$ (160/360). Of the nurses, $492(83.1 \%)$ were registered nurses, $78(13.2 \%)$ were charge nurses and $22(3.7 \%)$ were head nurses. Nurse evaluations are shown in table 1 .

The status of the 160 physicians is shown in table 1 . Of the 160 physicians, $45(28.1 \%)$ worked in emergency medicine, $35(21.9 \%)$ in internal medicine, 42 (26.3\%) in anaesthesia and $4(2.5 \%)$ in other specialties.

\section{Attitudes to human factors and safety}

The means and SDs of responses to the 65 items, and of the three-stage classifications, are shown in table 2. The five-point scale scores for the nine themes are shown in table 3. The information-sharing score was the highest and the confidence/assertion score was the lowest.

\section{Discrepancy of attitudes to human factors and safety}

In the questionnaire section concerning leadership, the mean score was $3.37 \pm 0.43$ for nurses and $3.12 \pm 0.39$ for physicians; the latter score was significantly lower. In addition, the mean score was $3.35 \pm 0.43$ for respondents with 24 months or less of a clinical career and $3.29 \pm 0.43$ for those with more than 24 months; the latter score was significantly lower (table 4 ).

For the questionnaire section concerning informationsharing, the mean score was $3.76 \pm 0.48$ for nurses and $3.85 \pm 0.54$ for physicians; the former score was significantly lower. In the questionnaire section concerning stress and fatigue, the mean score was $3.33 \pm 0.27$ for respondents with 24 months or less of a clinical career and $3.26 \pm 0.27$ for those with more than 24 months; the latter score was significantly lower (table 4).

For the questionnaire section concerning work value, the mean score was $3.37 \pm 0.33$ for respondents with 24 months or less of a clinical career and $3.43 \pm 0.30$ for those with more than 24 months; the former score was significantly lower (table 4).

In the section on error/procedural compliance, the mean score was $3.32 \pm 0.33$ for respondents with 24 months or less of a clinical career and $3.24 \pm 0.35$ for those with more than 24 months. In the section on error management, the mean score was $3.51 \pm 0.33$ for respondents with 24 months or less of a clinical career and $3.46 \pm 0.35$ for those with more than 24 months; the latter score was significantly lower (table 4 ).

There were no between-group differences in scores for confidence/assertion, teamwork or organisational climate. No gender-based differences were apparent.

\section{DISCUSSION}

This is the first attempt to survey the attitudes of healthcare providers working in acute care areas in South Korea in terms of human factors influencing patient safety. We identified the predominant attitudes of healthcare professionals working in such settings, the safety climate of hospitals in Korea, and differences between Korea and other countries. These are discussed below with reference to six areas: leadership and confidence/assertion, information-sharing and teamwork, awareness of stress and fatigue, work values and organisational climate, error/procedural compliance and error management, and discrepancies in attitudes.

\section{Leadership and confidence-assertion}

An organisation that shares responsibilities increases patient safety because high-level performance is assured when work is considered to be worthwhile. ${ }^{18} 19$ Leadership is important not only to senior staff but also to junior staff. The attitudes of healthcare professionals at all levels are vital. It is true that doctors play leading roles in patient care, especially in critical situations, but they depend heavily on their team members. ${ }^{20}$

In this study, $70.1 \%$ agreed with the statement that "Senior staff should encourage questions from junior staff" and $68.5 \%$ disagreed with "Doctors who encourage suggestions from team members are weak leaders". Thus, an egalitarian attitude and an opinion-gathering style were more positively viewed than a vertical and authoritarian approach. However, the scores were lower than those of a study on anaesthetists' attitudes conducted by Flin $e t a l^{12}$ based in the UK; the scores in that study were $96.0 \%$ and $95.0 \%$, respectively. Furthermore, in this study, only $13.8 \%$ disagreed with the statement "Successful medical team management is primarily a function of the doctor's medical and technical proficiency"; this is lower than the $67.0 \%$ in the study of Flin et al. ${ }^{12}$ Therefore, medical and nursing personnel in Korea often perceive the technical skills and competency of a leader as more important than non-technical skills.

The confidence/assertion items address superiorsubordinate relationships and the openness of leaders to questions and suggestions. ${ }^{1}{ }^{12}$ The score reflects the importance assigned to inclusion of junior staff members in decisions and conversations, ${ }^{1}{ }^{12}$ and also reflects the personal and organisational culture of the hierarchy. ${ }^{13}$

In this study, only $1.3 \%$ disagreed with the statement "In critical situations, I rely on my superiors to tell me 
Table 2 Attitudes of respondents to human factors and patient safety

\begin{tabular}{|c|c|c|c|c|}
\hline Items & Mean $\pm S D^{\star}$ & Disagree (\%) & Neutral (\%) & Agree (\%) \\
\hline \multicolumn{5}{|l|}{ Leadership structure } \\
\hline $\begin{array}{l}\text { Senior staff should encourage questions from junior medical and } \\
\text { nursing staff if appropriate }\end{array}$ & $3.85 \pm 0.81$ & 5.2 & 24.7 & 70.1 \\
\hline $\begin{array}{l}\text { Doctors who encourage suggestions from team members are weak } \\
\text { leaders }\end{array}$ & $2.29 \pm 0.84$ & 68.5 & 21.0 & 10.5 \\
\hline $\begin{array}{l}\text { Successful medical team management is primarily a function of the } \\
\text { doctor's medical and technical proficiency }\end{array}$ & $3.38 \pm 0.82$ & 13.8 & 38.8 & 47.3 \\
\hline Leadership of the medical team should rest with the medical staff & $3.18 \pm 0.91$ & 24.2 & 37.3 & 38.5 \\
\hline $\begin{array}{l}\text { There are no circumstances where a junior team member should } \\
\text { assume control }\end{array}$ & $2.43 \pm 0.91$ & 58.8 & 29.0 & 12.2 \\
\hline \multicolumn{5}{|l|}{ Confidence-assertion } \\
\hline $\begin{array}{l}\text { The senior person, if available, should take over and make all } \\
\text { decisions in life-threatening emergencies }\end{array}$ & $3.67 \pm 0.88$ & 11.4 & 20.2 & 68.4 \\
\hline $\begin{array}{l}\text { Junior team members should not question the decisions made by } \\
\text { senior personnel }\end{array}$ & $2.33 \pm 0.88$ & 63.6 & 26.1 & 10.3 \\
\hline $\begin{array}{l}\text { If I perceive a problem with the management of a patient, I will speak } \\
\text { up, regardless of who might be affected }\end{array}$ & $3.31 \pm 0.76$ & 14.1 & 42.7 & 43.2 \\
\hline In critical situations, I rely on my superiors to tell me what to do & $3.93 \pm 0.57$ & 1.3 & 16.2 & 82.4 \\
\hline $\begin{array}{l}\text { I sometimes feel uncomfortable telling team members from other } \\
\text { disciplines that they need to take some action }\end{array}$ & $3.18 \pm 0.79$ & 19.7 & 44.1 & 36.2 \\
\hline $\begin{array}{l}\text { Team members should not question the decisions or actions of senior } \\
\text { staff except when they threaten the safety of the patient management }\end{array}$ & $3.01 \pm 0.80$ & 27.1 & 45.1 & 27.8 \\
\hline $\begin{array}{l}\text { I always ask questions when I feel there is something I do not } \\
\text { understand }\end{array}$ & $3.63 \pm 0.71$ & 5.1 & 35.4 & 59.6 \\
\hline \multicolumn{5}{|l|}{ Information-sharing } \\
\hline $\begin{array}{l}\text { A regular debriefing of procedures and decisions after a session or } \\
\text { shift is an important part of developing and maintaining effective team } \\
\text { coordination }\end{array}$ & $3.99 \pm 0.70$ & 2.5 & 17.0 & 80.5 \\
\hline $\begin{array}{l}\text { Team members in charge should verbalise plans for procedures or } \\
\text { actions and should be sure that the information is understood and } \\
\text { acknowledged by others }\end{array}$ & $3.90 \pm 0.68$ & 2.7 & 20.6 & 76.7 \\
\hline $\begin{array}{l}\text { I am encouraged by my leaders and co-workers to report any } \\
\text { incidents I may observe }\end{array}$ & $3.54 \pm 0.73$ & 7.7 & 35.8 & 56.5 \\
\hline $\begin{array}{l}\text { The presession team briefing is important for safety and for effective } \\
\text { team management }\end{array}$ & $3.68 \pm 0.70$ & 4.1 & 32.2 & 63.7 \\
\hline \multicolumn{5}{|l|}{ Teamwork } \\
\hline $\begin{array}{l}\text { The only people qualified to give me feedback are members of my } \\
\text { own profession }\end{array}$ & $2.90 \pm 0.97$ & 39.1 & 31.0 & 29.8 \\
\hline $\begin{array}{l}\text { It is better to agree with other medical team members than to voice a } \\
\text { different opinion }\end{array}$ & $2.72 \pm 0.77$ & 38.6 & 46.1 & 15.3 \\
\hline $\begin{array}{l}\text { The doctor's responsibilities include coordination between his or her } \\
\text { work team and other support teams }\end{array}$ & $4.05 \pm 0.68$ & 1.5 & 15.8 & 82.7 \\
\hline $\begin{array}{l}\text { Medical team members share responsibilities for prioritising activities } \\
\text { in high workload situations }\end{array}$ & $3.94 \pm 0.67$ & 1.6 & 20.6 & 77.8 \\
\hline I enjoy working as part of a team & $3.49 \pm 0.71$ & 6.1 & 42.8 & 51.1 \\
\hline $\begin{array}{l}\text { To resolve conflicts, team members should openly discuss their } \\
\text { differences with each other }\end{array}$ & $3.82 \pm 0.69$ & 2.4 & 27.1 & 70.5 \\
\hline All members of the medical team are qualified to give me feedback & $3.48 \pm 0.68$ & 6.1 & 43.9 & 50.0 \\
\hline $\begin{array}{l}\text { The concept of all medical personnel working as a team does not } \\
\text { work at this hospital }\end{array}$ & $2.50 \pm 0.79$ & 54.1 & 36.4 & 9.6 \\
\hline $\begin{array}{l}\text { Effective medical team coordination requires members to take into } \\
\text { account the personalities of other team members }\end{array}$ & $3.80 \pm 0.61$ & 1.2 & 27.0 & 71.8 \\
\hline \multicolumn{5}{|l|}{ Stress and fatigue } \\
\hline $\begin{array}{l}\text { Even when tired, I perform effectively during critical phases of patient } \\
\text { care }\end{array}$ & $3.56 \pm 0.81$ & 9.7 & 32.1 & 58.2 \\
\hline $\begin{array}{l}\text { We should be aware of, and sensitive to, the personal problems of } \\
\text { other team members }\end{array}$ & $3.72 \pm 0.74$ & 6.3 & 25.9 & 67.8 \\
\hline $\begin{array}{l}\text { I let other team members know when my workload is becoming (or is } \\
\text { about to become) excessive }\end{array}$ & $3.35 \pm 0.85$ & 18.6 & 31.5 & 49.9 \\
\hline
\end{tabular}


Table 2 Continued

\begin{tabular}{|c|c|c|c|c|}
\hline Items & Mean $\pm S D^{*}$ & Disagree (\%) & Neutral (\%) & Agree (\%) \\
\hline $\begin{array}{l}\text { My decision-making is as good in emergencies as it is in routine } \\
\text { situations }\end{array}$ & $3.37 \pm 0.70$ & 9.0 & 46.9 & 44.0 \\
\hline I am more likely to make errors in tense or hostile situations & $3.17 \pm 0.89$ & 24.9 & 36.0 & 39.1 \\
\hline I am less effective when stressed or tired & $3.81 \pm 0.74$ & 3.9 & 26.9 & 69.3 \\
\hline $\begin{array}{l}\text { My performance is not adversely affected by working with an } \\
\text { inexperienced or less capable team member }\end{array}$ & $2.50 \pm 0.79$ & 54.4 & 35.5 & 10.1 \\
\hline $\begin{array}{l}\text { Team members should monitor each other for signs of stress or } \\
\text { tiredness }\end{array}$ & $3.83 \pm 0.65$ & 1.7 & 26.1 & 72.2 \\
\hline $\begin{array}{l}\text { I become irritated when I have to work with inexperienced medical } \\
\text { staff }\end{array}$ & $3.51 \pm 0.79$ & 8.4 & 41.3 & 50.3 \\
\hline $\begin{array}{l}\text { A truly professional team member can leave personal problems } \\
\text { behind when working in patient care }\end{array}$ & $3.99 \pm 0.65$ & 1.6 & 16.6 & 81.8 \\
\hline $\begin{array}{l}\text { Team members should feel obligated to mention their own } \\
\text { psychological stress or physical problems to other medical team } \\
\text { personnel before or during a shift or assignment }\end{array}$ & $3.13 \pm 0.79$ & 18.8 & 49.1 & 32.1 \\
\hline Personal problems can adversely affect my performance & $3.35 \pm 0.76$ & 12.1 & 43.4 & 44.5 \\
\hline \multicolumn{5}{|l|}{ Work values } \\
\hline Senior staff deserve extra benefits and privileges & $3.39 \pm 0.75$ & 10.8 & 41.8 & 47.5 \\
\hline I do my best work when people leave me alone & $3.40 \pm 0.78$ & 12.0 & 42.0 & 46.0 \\
\hline It bothers me when others do not respect my professional capabilities & $3.53 \pm 0.78$ & 9.7 & 35.4 & 54.9 \\
\hline I try to be a person whom others will enjoy working with & $4.01 \pm 0.61$ & 0.4 & 16.2 & 83.4 \\
\hline It is important that my competence be acknowledged by others & $3.74 \pm 0.66$ & 3.5 & 27.8 & 68.8 \\
\hline I value compliments about my work & $3.51 \pm 0.73$ & 6.4 & 42.8 & 50.8 \\
\hline As long as the work gets done, I do not care what others think of me & $2.65 \pm 0.84$ & 48.0 & 35.1 & 16.9 \\
\hline A good reputation in the medical field is important to me & $3.66 \pm 0.69$ & 3.6 & 35.6 & 60.8 \\
\hline $\begin{array}{l}\text { I value the goodwill of my fellow workers-I care that others see me } \\
\text { as friendly and cooperative }\end{array}$ & $3.73 \pm 0.63$ & 1.9 & 30.9 & 67.3 \\
\hline $\begin{array}{l}\text { It is an insult to be forced to wait unnecessarily for other members of } \\
\text { the medical team }\end{array}$ & $3.60 \pm 0.83$ & 8.8 & 35.4 & 55.8 \\
\hline $\begin{array}{l}\text { In the medical field, I get the respect that a person of my profession } \\
\text { deserves }\end{array}$ & $3.13 \pm 0.70$ & 14.6 & 57.2 & 28.2 \\
\hline \multicolumn{5}{|l|}{ Organisational climate } \\
\hline $\begin{array}{l}\text { The department provides adequate, timely information about events } \\
\text { in the hospital which might affect my work }\end{array}$ & $3.58 \pm 0.73$ & 6.9 & 33.8 & 59.3 \\
\hline Working in this hospital is like being part of a large family & $3.06 \pm 0.83$ & 23.1 & 47.3 & 29.5 \\
\hline Departmental leadership listens to staff and cares about our concerns & $3.38 \pm 0.84$ & 12.8 & 39.1 & 48.1 \\
\hline I am proud to work for this hospital & $3.10 \pm 0.78$ & 17.3 & 55.3 & 27.4 \\
\hline I like my job & $3.45 \pm 0.75$ & 7.0 & 45.2 & 47.7 \\
\hline $\begin{array}{l}\text { I am provided with adequate training to successfully accomplish my } \\
\text { job }\end{array}$ & $3.42 \pm 0.73$ & 9.5 & 42.2 & 48.3 \\
\hline \multicolumn{5}{|l|}{ Error/procedural compliance } \\
\hline Errors are a sign of incompetence & $3.05 \pm 0.87$ & 29.0 & 37.5 & 33.4 \\
\hline I am ashamed when I make a mistake in front of other team members & $3.29 \pm 0.80$ & 15.8 & 41.6 & 42.6 \\
\hline Procedures and policies are strictly followed in our department & $3.45 \pm 0.65$ & 5.1 & 46.9 & 48.0 \\
\hline Mistakes are handled appropriately in this hospital & $3.32 \pm 0.74$ & 10.2 & 48.8 & 41.0 \\
\hline Human error is inevitable & $3.57 \pm 0.70$ & 5.6 & 37.9 & 56.5 \\
\hline $\begin{array}{l}\text { Team members frequently disregard rules or guidelines (eg, hand } \\
\text { washing, treatment protocols/clinical pathways, sterile field) developed } \\
\text { for our department }\end{array}$ & $2.39 \pm 0.83$ & 62.1 & 27.8 & 10.1 \\
\hline \multicolumn{5}{|l|}{ Error management } \\
\hline $\begin{array}{l}\text { I rarely witness an error where one or more team members lack the } \\
\text { knowledge to perform the needed action }\end{array}$ & $2.85 \pm 0.75$ & 31.9 & 49.9 & 18.2 \\
\hline $\begin{array}{l}\text { Errors committed during patient management are not important, as } \\
\text { long as the patient improves }\end{array}$ & $2.18 \pm 0.69$ & 74.3 & 21.9 & 3.7 \\
\hline I make errors in the field & $3.12 \pm 0.70$ & 17.6 & 54.0 & 28.5 \\
\hline Medical errors are discussed to prevent recurrence & $3.89 \pm 0.64$ & 1.2 & 22.7 & 76.1 \\
\hline $\begin{array}{l}\text { A confidential reporting system that documents medical errors is } \\
\text { important for safety }\end{array}$ & $3.72 \pm 0.78$ & 4.9 & 31.4 & 63.7 \\
\hline
\end{tabular}


Table 3 Mean scores and reliability according to the nine themes

\begin{tabular}{|c|c|c|c|c|}
\hline Theme & Mean $\pm S D^{\star}$ & Maximum & Minimum & $\alpha$ \\
\hline Leadership structure & $3.31 \pm 0.43$ & 2.00 & 4.80 & 0.258 \\
\hline Confidence-assertion & $2.97 \pm 0.34$ & 1.71 & 4.43 & 0.325 \\
\hline Information-sharing & $3.78 \pm 0.49$ & 2.25 & 5.00 & 0.658 \\
\hline Teamwork & $3.61 \pm 0.37$ & 2.56 & 4.89 & 0.634 \\
\hline Stress and fatigue & $3.29 \pm 0.27$ & 2.42 & 4.25 & 0.347 \\
\hline Work value & $3.41 \pm 0.32$ & 2.45 & 4.45 & 0.570 \\
\hline Organisational climate & $3.33 \pm 0.52$ & 1.50 & 5.00 & 0.750 \\
\hline Error/procedural compliance & $3.27 \pm 0.35$ & 2.17 & 4.67 & 0.212 \\
\hline Error management & $3.48 \pm 0.34$ & 2.40 & 4.60 & 0.156 \\
\hline
\end{tabular}

*Means are calculated from the reversed scores when necessary so that the higher the score, the more positive the attitude.

$\alpha$, Cronbach's $\alpha$.

what to do" and $27.1 \%$ disagreed with "Team members should not question the decisions or actions of senior staff except when they threaten the safety of patient management". These scores were lower than those recorded by Flin et al, ${ }^{12}$ which were $74.0 \%$ and $66.0 \%$, respectively. This indicates that many healthcare professionals in Korea are highly dependent on decisions made by their seniors and that team structures and hierarchies within such structures are not even.

In addition, $63.6 \%$ disagreed with the statement "Junior team members should not question the decisions made by senior personnel" and $43.2 \%$ agreed with "If I perceive a problem with the management of a patient, I will speak up, regardless of who might be affected"; these scores are lower than those recorded by Flin et $a l^{12}$ which were $89.0 \%$ and $83.0 \%$, respectively. Thus, a rigid culture often exists in which workers feel uncomfortable about disclosing errors made by seniors or other staff members, and will not voice any difference of opinion with such persons.

\section{Information sharing and teamwork}

Information-sharing is important to maintain team activities via information exchange and regular briefings and debriefings. It also plays an important role in the maintenance of effective team coordination. ${ }^{1}{ }^{12}$ In general, our respondents exhibited positive attitudes toward information-sharing; medical personnel attach considerable importance to briefings, debriefings and consultations with other team members.

The teamwork items explored attitudes toward open discussion of the varying opinions of group members, and respect for the personalities and problems of others. ${ }^{1} 1218$ Medical errors are more common when teamwork is poor rather than good. ${ }^{21-23}$ Good teamwork avoids problems, affords higher performance, and shortens operative times. ${ }^{24}$

Overall, the attitude towards teamwork was good, but only $39.1 \%$ of respondents disagreed with the statement "The only people qualified to give me feedback are members of my own profession"; $38.6 \%$ disagreed with "It is better to agree with other medical team members than to voice a different opinion." These values were lower than those reported by Flin et al, ${ }^{12}$ which were $68.0 \%$ and $88.0 \%$, respectively. We thus found that Korean medical personnel tend to be less assertive in open discussions, with or without feedback from other team members. We assume that these results reflect the Korean culture; it is generally unacceptable to express opinions or to have discussions about colleagues.

In addition, only $51.1 \%$ of respondents reported that they enjoyed working as part of a team in their current working environment, and $54.1 \%$ disagreed with "The concept of all medical personnel working as a team

Table 4 Discrepancies of attitudes to human factors and patient safety

\begin{tabular}{|c|c|c|c|c|c|c|}
\hline \multirow[b]{2}{*}{ Theme } & \multirow[b]{2}{*}{ Group } & & \multirow[b]{2}{*}{$\mathrm{B} \pm \mathrm{SE}$} & \multicolumn{2}{|l|}{$95 \% \mathrm{Cl}$} & \multirow[b]{2}{*}{ p Value } \\
\hline & & & & Lower & Upper & \\
\hline \multirow[t]{2}{*}{ Leadership structure } & Occupation & Physician* & $-0.293 \pm 0.052$ & -0.395 & -0.190 & $<0.001$ \\
\hline & Clinical career & $\leq 24$ months $†$ & $0.132 \pm 0.033$ & 0.067 & 0.197 & $<0.001$ \\
\hline Information-sharing & Occupation & Physician & $0.134 \pm 0.062$ & 0.013 & 0.256 & 0.030 \\
\hline Stress and fatigue & Clinical career & $\leq 24$ months & $0.065 \pm 0.021$ & 0.023 & 0.107 & 0.002 \\
\hline Work values & Clinical career & $\leq 24$ months & $-0.064 \pm 0.025$ & -0.113 & -0.014 & 0.012 \\
\hline Error/procedural compliance & Clinical career & $\leq 24$ months & $0.092 \pm 0.027$ & 0.038 & 0.145 & 0.001 \\
\hline Error management & Clinical career & $\leq 24$ months & $0.055 \pm 0.027$ & 0.001 & 0.108 & 0.045 \\
\hline
\end{tabular}

*Reference group: Nurse.

†Reference group: Clinical career $>24$ months.

$\mathrm{B}$, parameter estimate. 
does not work at this hospital". It may be true that many Korean medical personnel feel that teamwork is currently ineffective and unsatisfactory. As mentioned above, this reflects the reluctance to voice an opinion contrary to that of a senior or other team member. This encourages ineffective and unsatisfactory teamwork.

\section{Stress and fatigue}

The questions on stress and fatigue explored the awareness of the negative effects of fatigue, stress and personal problems on performance, as well as of the significance of personal fallibility. ${ }^{112}{ }^{13}$ In this study, only $9.7 \%$ of respondents disagreed with the idea that fatigue negatively affected performance during critical phases of patient care and only $9.0 \%$ disagreed with the notion that fatigue negatively affected good decision-making both in emergencies and routine situations. A total of $39.1 \%$ of respondents agreed that errors were more probable in intense or hostile situations and $44.5 \%$ (thus, less than half) agreed that personal problems adversely affected performance.

Other studies on attitudes towards stress and fatigue showed that respondents tended to deny personal vulnerability to stressors, and played down the significance of stress and fatigue. Sexton $e t a l^{13}$ compared medical staff to pilots; the latter were more aware of the effects of stress. In addition, Flin $e t a l^{12}$ found that only $30-40 \%$ of respondents reported that they had been affected by stress and fatigue; answers to other items suggested denial of personal vulnerability to stressors in general. In this study, our respondents exhibited very low levels of awareness of the negative effects of fatigue, stress and personal problems on performance, in contrast to other studies. We assume that these results are attributable, at least in part, to the fact that many medical personnel have been trained to minimise the effects of personal stress and fatigue on achievement, both throughout their school years, and to ensure effective patient care after they become medical professionals. This reflects a cultural attitude: A person who is vulnerable to stress is considered to lack professionalism.

Many studies have shown that error is more likely and suboptimal patient care is more frequent when medical personnel are stressed, burnt out and/or dissatisfied. $^{3} 42526$ Therefore, the negative effects of fatigue, stress and personal problems must be appropriately recognised, and changes in organisational climates are necessary to reduce the incidence of errors.

\section{Work values and organisational climate}

Items on attitudes towards work explored awareness of and the perceived importance of professional recognition. ${ }^{12}$ Thus, questions about the organisational climate sought to evaluate the shared attitudes, beliefs and values held across an organisation and affinity for the job. ${ }^{12}$ A total of $50.8 \%$ of our respondents agreed with the statement "I value compliments about my work" and $60.8 \%$ agreed with "A good reputation in the medical field is important to me"; these values were lower than those reported by Flin $e t \mathrm{al}^{12}(91.0 \%$ and $82.0 \%$, respectively). This indicates that, in Korea, approximately half of all medical personnel do not attach importance to professional recognition. In addition, only $28.2 \%$ agreed with the statement "I get the respect that a person of my profession deserves"; this figure is much lower than the $66.0 \%$ reported in the study by Flin et al. ${ }^{12}$ This indicates that the level of job satisfaction is very low.

In terms of the organisational climate, only $29.5 \%$ agreed with the statement "Working in this hospital is like being part of a large family" and only $27.4 \%$ agreed with "I am proud to work for this hospital"; these figures were even lower than the low results obtained by Flin et $a l^{12}(41.0 \%$ and $58.0 \%$, respectively). In addition, $47.4 \%$ agreed with 'I like my job'; this is much lower than the $90 \%$ reported by Flin et al. ${ }^{12}$ Fewer than $50 \%$ of respondents in this study replied positively to most other items in this section. Thus, only a few respondents take pride in their organisations, profess affinity for their jobs and hold positive familial viewpoints towards their organisations.

Work values and organisational climate reflect the level of satisfaction with the job and the working environment. Enhancing job satisfaction improves patient safety; teamwork and communication are encouraged. ${ }^{12} 27$ In addition, low satisfaction with the job or working environment causes poor communication and higher levels of work stress, eventually triggering higher accident rates, burnout and adverse patient quality-of-care issues, as mentioned above. ${ }^{27} 28$

The low level of job and work environment satisfaction evident in this study will negatively affect the general attitude towards human factors because poor satisfaction is itself a deleterious stressor. Therefore, integrated organisational efforts are essential to improve job satisfaction, improving patient safety.

\section{Error/procedural compliance and error management}

This section explored attitudes towards the recognition that human errors are inevitable and that errors do not imply lack of knowledge or incompetence. ${ }^{29}$ Hospital error management systems seek to prevent recurrence via error reports and cause analyses. ${ }^{12}$ Many of our respondent medical personnel considered that errors reflected a lack of knowledge and were a sign of incompetence. In addition, only $28.5 \%$ agreed with the statement 'I make errors' and only $56.5 \%$ agreed with 'Human error is inevitable'.

Error-reporting systems generally rely on selfreporting, and avoidance of disclosure caused by feelings of guilt, blame and shame is a major obstacle to the effectiveness of such systems. ${ }^{30} 31$ Therefore, improvements to the culture of error disclosure, and new confidential error reporting systems, are required to ensure better and more effective error reporting. ${ }^{32-34}$

Of all respondents, $48 \%$ considered that policies and procedures were strictly followed by the safety 
management systems of their hospital, but only $41 \%$ agreed with 'Mistakes are handled appropriately in this hospital'. This indicates a lack of appropriate error management. In the study by Flin $e t a l,{ }^{12}$ only $39 \%$ of respondents reported that mistakes were handled appropriately; development and improvement of hospital safety management systems was considered necessary.

\section{Discrepancy of attitudes to teamwork and safety}

Helmreich and Davies ${ }^{1}$ reported that nurses and anaesthetists worked within less hierarchical structures than did surgeons, and found differences in attitudes towards leadership by medical position and specialty. In this study, physicians and other respondents with more than 24 months of clinical experience exhibited autocratic leadership styles. This is explained by the prevailing culture, which features a rigid hierarchy of physicians, with more experienced personnel at the top.

Nurses scored information-sharing lower than physicians; such sharing is important in the teamwork context. This finding is similar to those of other teamwork studies, which found differences in the perceived extents of teamwork and openness of communication among nurses and physicians in the same medical teams. ${ }^{13} 35-37$

More experienced healthcare professionals had relatively less tolerant attitudes towards stress and fatigue, incompetent error/procedural compliance and poor error management. The reason may be that, as careers progress and positions become more senior, medical personnel assimilate the general culture: Any negative effect of stress and fatigue on work and performance reflects incompetence and the individual is to blame. In addition, we presume that senior personnel know that proper error management systems encouraging errors to be openly disclosed and discussed are lacking. Several studies have reported differences in attitudes towards stress and fatigue among medical personnel, by position or specialty. Sexton et $a l^{13}$ found that more surgical consultants, compared to doctors in other positions or specialties, denied any effects of stress and fatigue. In addition, Helmreich and Davies ${ }^{1}$ showed that anaesthetists considered stress and fatigue to be more problematic than did other medical subgroups.

The perceived importance of professional recognition was relatively low among less experienced medical personnel. This is attributable to the rigid hierarchy, in which the decisions of senior personnel are implemented without question.

\section{Limitations and future research suggestion}

There are several limitations to our study. First, the data were gathered in only nine Korean teaching hospitals, and thus may not be generalisable to other settings. Additional surveys are needed to assess the attitudes of medical personnel working in other teaching hospitals and other types of medical institutions. Second, the numbers of respondents in the two groups (physicians and nurses) differed. Third, comparisons between groups are of limited utility because of the low reliabilities of the chosen themes. Reliabilities have varied among other studies that employed ORMAQ. In this study, we used ORMAQ to compare the attitudes of Korean healthcare professionals with those of other countries. Universal measurement tools which can be used in all healthcare settings across the world are needed. Such tools could be used to establish strategies, evaluate training and make comparisons between different groups or countries. Fourth, safety management systems and the overall work climate may differ between hospitals; however, we investigated these factors in combination because we wished to obtain an overview of attitudes in Korea. Finally, other factors, such as educational experience and position, may influence the attitudes of medical personnel towards human factors influencing patient safety.

\section{CONCLUSIONS}

We explored institutional cultures, as well as the predominant attitudes towards and opinions about human factors affecting patient safety, among medical personnel working in critical care settings in nine Korean teaching hospitals We found a tendency to consider the technical skill and competence of leaders as more important than human factors in medical care; a rigid culture prohibiting open discussion, feedback and airing of different opinions with colleagues; a high dependency on decisions of senior staff members; low recognition of the negative effects of fatigue, stress and personal problems; poor satisfaction in terms of teamwork; low pride in the organisation; poor job satisfaction; and limited perception that professional recognition was important. In addition, many respondents considered that errors were attributable to a lack of knowledge, being a sign of incompetence, and were often reluctant to disclose such errors. In addition, hospital error management systems are inadequate. Differences in attitudes towards leadership and information-sharing were evident between the professional groups, and the duration of clinical experience influenced attitudes towards leadership, stress and fatigue, the value of work and error.

Our findings serve as baseline data that can be used to develop staff training programmes and systems increasing patient safety.

Team-oriented medical simulations (crisis resource management using a simulator) effectively convince team members of the importance of human factors. ${ }^{38-40}$ This type of training is urgently needed to break down the rigid culture described above and should be included to the core curriculum. Senior personnel should be trained first; a cultural change is needed within the hierarchy, who will then advocate for changes in organisational cultures. Personnel with long-clinical careers must be the first group to be trained; their negative attitudes towards leadership, stress and fatigue, the value of work and error management must first be altered. 
Author affiliations

${ }^{1}$ Department of Emergency Medicine, Chung-Ang University College of Medicine, Seoul, Korea

${ }^{2}$ Department of Emergency Medicine, College of Medicine, Hanyang University, Seoul, Korea

${ }^{3}$ Department of Emergency Medicine, Yonsei University College of Medicine, Seoul, Korea

${ }^{4}$ Department of Emergency Medicine, Kangdong Sacred Heart Hospital, College of Medicine, Hallym University Medical Center, Seoul, Korea ${ }^{5}$ Department of Emergency Medicine, Soonchunhyang University Seoul Hospital, Seoul, Korea

${ }^{6}$ Department of Emergency Medicine, College of Medicine, Ewha Womans University, Seoul, Korea

${ }^{7}$ Department of Emergency Medicine, Korea University College of Medicine, Seoul, Korea

${ }^{8}$ Department of Emergency Medicine, College of Medicine, Seoul National University, Seoul Metropolitan Boramae Medical Center, Seoul, Korea

Contributors SEK, CWK, SJL, DHL and THL were involved in the conception and design. SJL, HJC, HSC, JYR, HYJ, YHC, SJK and JHJ were involved in the acquisition, analysis and interpretation of data. SEK, CWK, DHL and JHO contributed to the drafting and writing of the article. All authors participated in the review and approval of the final version of the manuscript.

Funding This research received no specific grant from any funding agency in the public, commercial or not-for-profit sectors.

Competing interests None declared.

Ethics approval Institutional review board of the Chung-Ang University Hospital.

Provenance and peer review Not commissioned; externally peer reviewed.

Data sharing statement No additional data are available.

Open Access This is an Open Access article distributed in accordance with the Creative Commons Attribution Non Commercial (CC BY-NC 4.0) license, which permits others to distribute, remix, adapt, build upon this work noncommercially, and license their derivative works on different terms, provided the original work is properly cited and the use is non-commercial. See: http:// creativecommons.org/licenses/by-nc/4.0/

\section{REFERENCES}

1. Helmreich R, Davies J. Human factors in the operating room: interpersonal determinants of safety, efficiency and morale. Bailliere's Clin Anaesthesiology 1996;10:277-95.

2. Fletcher G, McGeorge P, Flin R, et al. The role of non-technical skills in anaesthesia: a review of current literature. $\mathrm{Br} J$ Anaesth 2002;88:418-29.

3. Gaba D, Howard S, Jump B. Production pressure in the work environment. California anaesthesiologists' attitudes and experiences. Anesthesiology 1994;81:488-500.

4. Howard SK, Rosekind MR, Katz JD, et al. Fatigue in Anesthesia: implications and strategies for patient and provider safety. Anesthesiology 2002;97:1281-94.

5. Gaba D, Maxwell M, DeAnda A. Anesthetic mishaps: breaking the chain of accident evolution. Anesthesiology 1987;66:670-6.

6. Suresh G, Horbar JD, Plsek P, et al. Voluntary anonymous reporting of medical errors for neonatal intensive care. Pediatrics 2004;113:1609-18.

7. Donchin $\mathrm{Y}$, Gopher D, Olin M, et al. A look into the nature and causes of human errors in the intensive care unit. Crit Care Med 1995;23:294-300

8. Reader T, Flin $\mathrm{R}$, Lauche $\mathrm{K}$, et al. Non-technical skills in the intensive care unit. Br J Anaesth 2006;96:551-9.

9. Speroff T, Nwosu S, Greevy R, et al. Organisational culture: variation across hospitals and connection to patient safety climate. Qual Saf Health Care 2010;19:592-6.

10. Singer SJ, Falwell A, Gaba DM, et al. Identifying organizational cultures that promote patient safety. Health Care Manage Rev 2009;34:300-11.

11. Helmreich R, Schaefer HG. Team performance in the operating room. In: Bogner M, ed. Human Error in Medicine. Hillsdale, NJ: Erlbaum, 1994:225-53.

12. Flin R, Fletcher G, McGeorge $P$, et al. Anaesthetists' attitudes to teamwork and safety. Anaesthesia 2003;58:233-42.
13. Sexton JB, Thomas EJ, Helmreich RL. Error, stress, and teamwork in medicine and aviation: cross sectional surveys. BMJ 2000;320:745-9.

14. Gallego B, Westbrook MT, Dunn AG, et al. Investigating patient safety culture across a health system: multilevel modelling of differences associated with service types and staff demographics. Int J Qual Health Care 2012;24:311-20.

15. Helmreich R, Sexton B, Merritt A. The Operating Room Management Attitudes Questionnaire (ORMAQ). University of Texas Aerospace Crew Research Project Technical Report 97-6. Austin: The University of Texas, 1997.

16. Kim J, An K, Kim MK, et al. Nurses' perception of error reporting and patient safety culture in Korea. West J Nurs Res 2007;29:827-44.

17. Kim KJ, Han JS, Seo MS, et al. Relationship between intra-organizational communication satisfaction and safety attitude of nurses. J Korean Acad Nurs Admin 2012;18:213-21.

18. Manser T. Teamwork and patient safety in dynamic domains of healthcare: a review of the literature. Acta Anaesthesiol Scand 2009;53:143-51.

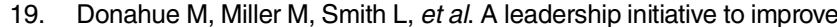
communication and enhance safety. Am J Med Qual 2011;26:206-11.

20. Carroll J, Edmondson A. Leading organisational learning in health care. Qual Saf Health Care 2001;11:51-6.

21. Lingard L, Espin S, Whyte S, et al. Communication failures in the operating room: an observational classification of recurrent types and effects. Qual Saf Health Care 2004:13:330-4.

22. Wiegmann DA, ElBardissi AW, Dearani JA, et al. Disruptions in surgical flow and their relationship to surgical errors: an exploratory investigation. Surgery 2007;142:658-65.

23. Pronovost PJ, Thompson DA, Holzmueller CG, et al. Toward learning from patient safety reporting systems. J Crit Care 2006;21:305-15.

24. Catchpole KR, Giddings AE, Wilkinson M, et al. Improving patient safety by identifying latent failures in successful operations. Surgery 2007;142:102-10.

25. Morris G, Morris R. Anaesthesia and fatigue: an analysis of the first 10 years of the Australian Incident Monitoring Study 1987-97. Anaesth Intensive Care 2000;28:300-4.

26. Williams ES, Manwell LB, Konrad TR, et al. The relationship of organizational culture, stress, satisfaction, and burnout with physician-reported error and suboptimal patient care: results from the MEMO study. Health Care Manage Rev 2007;32:203-12.

27. Gershon RR, Stone PW, Bakken S, et al. Measurement of organizational culture and climate in healthcare. $J$ Nurs $A d m$ 2004:34:33-40.

28. Clarke SP, Rockett JL, Sloane DM, et al. Organizational climate, staffing, and safety equipment as predictors of needle-stick injuries and near-misses in hospital nurses. Am J Infect Control 2002;30:207-16.

29. Kohn L, Corrigan J, Donaldson M, eds. To err is human: building a safer health system. Washington DC: National Academy of Sciences, 2000.

30. Gallagher TH, Waterman AD, Ebers AG, et al. Patients' and physicians' attitudes regarding the disclosure of medical errors. JAMA 2003;289:1001-7.

31. Kaldjian LC, Jones EW, Rosenthal GE, et al. An empirically derived taxonomy of factors affecting physicians' willingness to disclose medical errors. J Gen Intern Med 2006;21:942-8.

32. Wood KE, Nash DB. Mandatory state-based error-reporting systems: current and future prospects. Am J Med Qual 2005;20:297-303.

33. Leape LL. Reporting of adverse events. N Engl J Med 2002;347:1633-8.

34. Abstoss KM, Shaw BE, Owens TA, et al. Increasing medication error reporting rates while reducing harm through simultaneous cultural and system-level interventions in an intensive care unit. BMJ Qual Saf 2011;20:914-22.

35. Miller PA. Nurse-physician collaboration in an intensive care unit. Am J Crit Care 2001;10:341-50.

36. Thomas EJ, Sexton JB, Helmreich RL. Discrepant attitudes about teamwork among critical care nurses and physicians. Crit Care Med 2003;31:956-9.

37. O'Leary KJ, Ritter CD, Wheeler $\mathrm{H}$, et al. Teamwork on inpatient medical units: assessing attitudes and barriers. Qual Saf Health Care 2010;19:117-21.

38. Schaefer HG, Helmreich RL. The importance of human factors in the operating room. Anesthesiology 1994;80:479.

39. Aggarwal R, Mytton OT, Derbrew M, et al. Training and simulation for patient safety. Qual Saf Health Care 2010;19(Suppl 2):i34-43.

40. Gordon M, Darbyshire D, Baker P. Non-technical skills training to enhance patient safety: a systematic review. Med Educ 2012;46:1042-54. 